\title{
Intervenção comunitária e redução da vulnerabilidade de mulheres às DST/ Aids em
} São Paulo, SP Community based intervention and reduction
of women's vulnerability to STD/AIDS in Brazil

\author{
Regina Figueiredo e José Ricardo CM Ayres ${ }^{b}$
}

${ }^{a}$ Faculdade de Filosofia, Letras e Ciências Humanas da Universidade de São Paulo. São Paulo, SP, Brasil. ${ }^{b}$ Departamento de Medicina Preventiva da Faculdade de Medicina da Universidade de São Paulo. São Paulo, SP, Brasil

\section{Descritores}

Mulheres. Síndrome de

imunodeficiência adquirida, prevenção. Doenças sexualmente transmissíveis, prevenção. Participação comunitária. Vulnerabilidade. Fatores socioeconômicos. Áreas de pobreza. Promoção da saúde. Educação em saúde. Avaliação de resultado de ações preventivas. Gênero.

\section{Resumo}

\section{Objetivos}

Com o aumento do número de casos notificados de Aids em mulheres, as intervenções comunitárias, que são fundamentais nesse contexto, são poucas e raramente avaliadas. Assim, objetivou-se realizar um estudo-intervenção de base comunitária, buscando desenvolver e avaliar um conjunto de ações de prevenção das DST e da Aids voltadas a atingir a vulnerabilidade da população feminina de baixa renda.

\section{Métodos}

O estudo foi realizado na favela Monte Azul, na cidade de São Paulo, SP, no período de um ano (1998-1999). Foram desenvolvidas as seguintes ações: treinamento de profissionais de saúde do ambulatório local, disponibilidade de recursos preventivos (camisinha masculina e feminina), realização de grupos educativos, distribuição de materiais educativos e realização de programas na rádio comunitária. Para avaliar a intervenção, foram analisados dados provenientes de quatro diferentes instrumentos de investigação: pré e pós-teste sobre capacitação de profissionais de saúde para o trabalho preventivo, monitoramento de retirada de preservativos, observação participante das atividades comunitárias e registro de depoimentos espontâneos dos profissionais de saúde e população-alvo durante as atividades.

\section{Resultados}

Entre os achados do estudo, destacam-se o aumento da demanda pela camisinha masculina e o interesse pela camisinha feminina; diferenças relevantes relacionadas a gênero e idade e à adesão às atividades propostas; e bons resultados na sensibilização e capacitação dos profissionais de saúde, embora com limites na manutenção de seu envolvimento com as atividades preventivas.

\section{Conclusões}

As estratégias que corresponderam aos códigos, às demandas e aos interesses específicos da cultura local, principalmente em relação a papéis de gênero, tiveram sucesso como ações preventivas. A sobrecarga dos profissionais de saúde do ambulatório local mostrou-se um limite importante para uma ação preventiva sustentada.
Correspondência para/Correspondence to: Regina Figueiredo

Rua Juranda, 50, casa 5

05442-070 São Paulo, SP, Brasil

E-mail: reginafigueiredo@uol.com.br
Pesquisa financiada pelo World AIDS Foundation (WAF n. 118/96-032; n.168 n.98-026) e pelo Programa Estadual de DST/Aids da Secretaria de Saúde do Estado de São Paulo.

Edição subvencionada pela Fundação de Amparo à Pesquisa do Estado de São Paulo (Fapesp - Processo nº0/7406-2). Recebido em 22/1/2001. Reformulado em 17/9/2001. Aprovado em 26/3/2002. 


\section{Keywords}

Women. Acquired immunodeficiency

syndrome, prevention \& control.

Sexually transmitted diseases,

prevention \& control. Community

participation. Vulnerability.

Socioeconomic factors. Poverty areas.

Health promotion. Health education.

Result evaluation of preventive

actions. Gender.

\begin{abstract}

\section{Objectives}

Despite the growing number of AIDS cases in women reported, community-based interventions, which are essential in this context, are scarce and rarely evaluated. The aim of this study was to carry out a community-based research intervention, to develop and evaluate a set of STD/AIDS prevention actions targeting the vulnerability of low income women population.
\end{abstract}

\section{Methods}

The study was carried out in Monte Azul slum in the city of São Paulo, SP, Brazil, in the period 1998-1999. The following actions were put in place: training of health professionals from the local outpatient clinic, availability of prevention resources (male and female condoms), educational groups, educational materials and community radio programs. For evaluating intervention, data from four different research instruments were assessed: pre and post training testing of health professionals, monitoring of condom supply, direct observation of community activities, and record of health professionals and target population's voluntary statements during activities.

\section{Results}

It was observed an increase in demand for male condom and an interest in female condoms. There were relevant gender and age differences in adhering to proposed activities. Although there were good results regarding sensitization and training of health professionals, their involvement in prevention activities was limited.

\section{Conclusions}

Strategies relating to codes, demands and specific interests of the local society, especially those related to gender roles, have successfully performed as preventive actions. Health professionals'overwork at the local outpatient clinic proved to be an important limitation for maintaining preventive actions.

\section{INTRODUÇÃO}

Em anos recentes, há no Brasil uma "pauperização" e "feminização" dos casos de infecção pelo vírus da imunodeficiência humana (HIV). ${ }^{6}$ Duas possíveis explicações seriam a redução da transmissão sangüínea e sexual homossexual decorrentes das primeiras estratégias de prevenção e a postergação do início das campanhas e ações preventivas visando ao público heterossexual, inclusive feminino. ${ }^{7}$

O crescimento da transmissão heterossexual foi abrupto, passando de $6 \%$ em 1990 para $28 \%$ dos casos de Aids registrados no País em 1998, ${ }^{11}$ fato que acompanhou o crescimento dos casos notificados de infecção entre mulheres. No Estado de São Paulo, a Aids configurou-se como primeira causa de morte entre mulheres de 20 a 35 anos de idade de 1994 até a introdução dos anti-retrovirais na rede pública de saúde, em 1997. ${ }^{12}$ A razão de casos masculinos e femininos vem diminuindo rapidamente. Na cidade de São Paulo, passou-se, em cerca de dez anos, de uma relação de 25 casos masculinos para cada caso feminino para dois casos masculinos para cada caso feminino. ${ }^{14}$

As mulheres adquirem Aids por meio de contatos sexuais esporádicos, pela prestação de serviços sexuais remunerados, mas, cada vez mais, com seus parceiros fixos, tanto namorados quanto maridos. ${ }^{15}$

Desde 1994, o Centro de Referência e Treinamento em Aids (CRTA) da Secretaria de Estado da Saúde de São Paulo já apontava que quase metade (45\%) dos casos femininos de Aids notificados nesse Estado era de mulheres de baixa renda que estavam fora do mercado de trabalho, a maioria (70\%) dona de casa, monogâmica e com baixa escolaridade. ${ }^{4}$

Sob a motivação das tendências da epidemia de Aids anteriormente expostas e dos desafios que trazem para a prevenção, foi realizado, entre 1996 e 1998, um estudo qualitativo ${ }^{9}$ com a população feminina moradora da favela Monte Azul, na zona Sul da cidade de São Paulo. Essa favela, existente desde 1965 , tem área de $23.000 \mathrm{~m}^{2}$, e, segundo a Associação Comunitária Monte Azul (ACOMA), organização que agrupa pessoas físicas e financia atividades sociais no local, nela residem atualmente cerca de 445 famílias, num total de aproximadamente 2.900 pessoas.

Essa favela possui uma especificidade bastante interessante para o desenvolvimento de trabalhos comunitários. Pelo empenho da associação comunitá- 
ria e da organização de seus moradores, foram construídos diversos equipamentos sociais, como creches, pré-escolas, oficina de marcenaria, tecelagem, reciclagem de papel, padaria e outros.

Entre esses equipamentos, há na favela uma unidade de saúde, o Ambulatório Monte Azul, que trabalha com profissionais remunerados pela Associação Comunitária Monte Azul (Acoma), desenvolvendo atendimento em nível básico, principalmente para mulheres e crianças, ações de prevenção, como o prénatal, atendimento ginecológico, incluindo exame preventivo de câncer, contracepção, com colocação de dispositivos intra-uterinos e venda de pílulas anticoncepcionais e injeções hormonais anticonceptivas. Esse ambulatório já realizou, também, parto normal em suas próprias dependências, serviço desativado no momento.

No estudo anteriormente citado, ${ }^{9}$ ficou demonstrado que relações de gênero ancoradas em moldes bastante tradicionais predominavam no universo das mulheres da comunidade da favela Monte Azul, compondo aspectos socioculturais favorecedores da vulnerabilidade que transparece nos dados epidemiológicos sobre Aids entre mulheres. A partir dessa constatação é que foi proposto o presente trabalho, que tem por objetivo apresentar os resultados da execução, da aceitação e das repercussões de ações preventivas de DST/Aids entre mulheres da comunidade da favela Monte Azul, procurando-se discutir a efetividade e o rendimento das atividades e estratégias adotadas, refletir sobre intervenções preventivas no âmbito comunitário de modo geral e indicar possíveis determinantes de seus resultados.

\section{MÉTODOS}

\section{Contexto da pesquisa}

O presente estudo parte da premissa de que, intimamente relacionada às questões de gênero, a prevenção da infecção pelo HIV entre mulheres depende da sensibilização conjunta de homens e mulheres. Essa premissa está baseada na percepção de que a rejeição e o uso inconsistente do preservativo pelo público feminino têm ocorrido, entre outros motivos, pela recusa masculina em utilizá-lo e pelo receio, entre as mulheres, de comportamentos violentos por parte de seus parceiros. ${ }^{3}$ Por isso, optou-se por realizar um trabalho comunitário na favela Monte Azul, procurando tratar da prevenção no âmbito do cotidiano das relações entre homens e mulheres e integrando-a não apenas a temas como sexualidade e DST, em geral, mas também à gravidez e contracepção, destacadas preocupações cotidianas de mulheres e casais.
A vulnerabilidade de um grupo populacional à epidemia de HIV é definida pelo conjunto das características macropolíticas, econômicas e socioculturais que reforçam ou diluem o risco individual. ${ }^{1,10}$

Na pesquisa anterior, foi constada a alta vulnerabilidade das mulheres da favela às doenças sexualmente transmissíveis (DST). Conforme o estudo, isto está relacionado à formação cultural de sua população, constituída predominantemente de pessoas oriundas de regiões rurais do Nordeste brasileiro (ou descendentes destes em primeira geração) que migraram nas décadas de 1970 e 1980 . Nesse grupo, os papéis masculino e feminino desempenhados tendem a se manter conforme o modelo rural tradicional, tanto nas relações domésticas, quanto com relação aos assuntos íntimos do casal, incluindo a sexualidade e as práticas sexuais e afetivas. Paralelamente à persistência dos papéis tradicionais de gênero, no meio urbano ocorre aumento da rede de parceria sexual, com maior instabilidade dos relacionamentos homem-mulher.

Embora não se possam atribuir integralmente à cultura de origem as atitudes e os comportamentos em relação aos cuidados de saúde, o estudo mostrou que, além da manutenção dos papéis tradicionais de gênero, essa população trouxe hábitos próprios de cuidados com a saúde. Suas práticas preventivas estão bastante alicerçadas em prescrições comportamentais, alimentares e religiosas populares da tradição oral, o que pode ser compreendido pela baixa cobertura de equipamentos públicos de saúde em suas localidades até a ocasião em que migraram. Essas famílias reproduziram na educação de seus descendentes hábitos de cuidado com a saúde que se caracterizam por ser muito mais curativos do que preventivos e em que a procura de equipamentos de saúde tende a ocorrer apenas no evento doença. É assim, por exemplo, que a utilização de contracepção ocorre, freqüentemente, após a primeira gestação, iniciando-se a prática sexual sem nenhum tipo de prevenção, inclusive com relação às DST e à Aids.

A vinda para a metrópole industrial do Sudeste e o contato com uma rede de serviços de saúde pública mais disponível alteraram alguns comportamentos, como foi verificado numa maior adesão à prevenção do câncer do colo uterino (com a realização do papanicolau). Essas mudanças não parecem, porém, ter atingido todas as dimensões da saúde sexual e reprodutiva, principalmente aquelas que dependem de mudanças também nas relações com os parceiros.

Essas características, somadas à pobreza, à situação de desemprego, ao perfil informal dos traba- 
lhos remunerados realizados, à baixa escolaridade e à dependência dos equipamentos sociais públicos, compõem um quadro de expressiva vulnerabilidade da população feminina da favela Monte Azul às DST e à Aids.

Tal situação ressalta a necessidade de estratégias que não se limitem à disponibilização de informação sobre a prevenção, com a chamada "conscientização" da população sobre o problema. É necessário trabalhar as pré-disposições culturais e os limites materiais para práticas protegidas (vulnerabilidade socioeconômica), assim como incrementar serviços e programas capazes de dar acesso a essas discussões e aos meios preventivos disponíveis (vulnerabilidade programática), para que, no plano de suas atitudes e práticas pessoais (vulnerabilidade individual), essas mulheres possam, de fato, prevenir-se da infecção pelo HIV. Cabe destacar também a importância de atuar não apenas com mulheres adultas mas também com as adolescentes que estão formando hábitos e iniciando suas práticas sexuais e que constituem parcela significativa das mulheres infectadas. ${ }^{5}$

Nesse sentido, o desenho do projeto configurouse como o de um estudo-intervenção de redução de vulnerabilidade de base comunitária. Foram desenvolvidas, no período de junho de 1998 a agosto de 1999, na favela Monte Azul, várias atividades dirigidas aos profissionais do ambulatório local e à população residente na favela, divididas, para efeitos de intervenção e avaliação, conforme a seguir descritas.

\section{Atividades com a equipe de profissionais do ambulatório comunitário}

Foram reunidos, de um total de 20, 18 (90\%) profissionais do ambulatório, em dois encontros para uma capacitação dada por aula expositiva, dinâmicas de grupo e discussão. Esses encontros abordaram os seguintes conteúdos: o perfil cultural, reprodutivo e sexual característico das mulheres residentes nessa favela; a importância da prevenção das DST e da Aids; a vulnerabilidade feminina e as relações de gênero; as possibilidades de atuação desses profissionais no atendimento ginecológico e contraceptivo cotidiano; e as conseqüências comportamentais e/ou físicas do uso de cada método contraceptivo com relação à exposição às DST e à Aids com base em Figueiredo ${ }^{8} \mathrm{e}$ Mueller \& Wasserheit. ${ }^{13}$

$\mathrm{Na}$ capacitação e em contatos individuais com a coordenadora do ambulatório e sua equipe, foram dadas instruções sobre os materiais disponibilizados pelo projeto e a importância de sua utilização e divulgação: camisinhas masculinas (disponíveis ao longo de todo o período do estudo e até a presente data); camisinhas femininas (disponíveis durante oito meses); diafragmas, conjuntamente com espermicidas (ainda disponíveis); e folhetos educativos sobre prevenção de DST e Aids, uso de camisinha feminina e utilização da contracepção de emergência (para casos de falha do preservativo). Outros materiais, como cartazes, filmes educativos abordando órgãos sexuais e reprodutivos, métodos contraceptivos, prevenção às DST e à Aids e relações de gênero, também foram colocados à disposição para utilização em sala de espera.

A avaliação dos efeitos da capacitação e desses contatos e instruções foi feita por meio de um questionário estruturado, para auto-aplicação, preenchido imediatamente antes da capacitação e reaplicado três meses depois, ao qual se acoplou também um teste prático sobre colocação da camisinha, aplicado e avaliado pela equipe da pesquisa. Com esses instrumentos, procurou-se identificar alterações na percepção de risco individual e da clientela, mudanças em suas práticas de trabalho e informação sobre manuseio e uso do preservativo e aquisição de habilidades no uso (e ensino do uso) do preservativo. Ao todo, 18 profissionais participaram da capacitação, todos responderam ao pré-teste, e 11 responderam ao pós-teste. A avaliação baseada nesse instrumental foi enriquecida com observação direta a partir de conversas individuais informais e atenção aos comportamentos, reações e aderência ao projeto ao longo do período da intervenção.

\section{Atividades com a comunidade residente}

Para o trabalho com mulheres, homens e adolescentes, foi realizado um levantamento preliminar sobre o interesse, a disponibilidade e os melhores horários para participação em grupos educativos. Esse levantamento foi feito por um questionário rápido, respondido por 132 famílias residentes (cerca de $30 \%$ do total), selecionadas por sorteio, sem casos de recusa. A partir dos horários disponíveis verificados nos questionários, foram agendados 12 grupos educativos em datas diferentes para serem realizados em duas horas cada (quatro para mulheres, quatro para homens e quatro para adolescentes). Essas oficinas foram divulgadas para toda a comunidade por folhetos e cartazes afixados e por sistema de alto falantes, já instalado e espalhado por toda a favela.

O critério de participação das pessoas foi espontâneo, sem um número pré-definido de participantes. Assim, procurou-se avaliar o interesse, a busca e a viabilização dos grupos. 


\section{Grupos com adolescentes}

A metodologia proposta para a realização de cada um dos quatro grupos propostos foi a utilização de técnicas de grupo participativas, explorando: relações de gênero, sexualidade, prevenção das DST e Aids e da gravidez indesejada e uso de camisinhas. Essas oficinas foram marcadas no galpão de reuniões e de depósito de materiais (três encontros) e na sede da Associação Comunitária Monte Azul (um encontro). A participação nos grupos foi completamente livre, integrando todos os que comparecessem, independentemente da idade.

\section{Grupos com mulheres}

Os quatro grupos para mulheres adultas agendados foram planejados com as mesmas técnicas e conteúdos dos grupos de adolescentes, porém, devido à ausência de procura (conforme será comentado em Resultados), foram realizados como atividade de sala de espera do ambulatório, com a presença de algumas mulheres vindas especialmente para o grupo junto àquelas que aguardavam suas consultas. Por esse motivo, tais grupos terminaram por mesclar as técnicas expositiva e participativa. Apesar da mudança no local e na forma de envolvimento das mulheres participantes, o conteúdo desses encontros se manteve: prevenção às DST e à Aids, gravidez indesejada e vírus do papiloma humano (HPV), manuseio da camisinha masculina e feminina e contracepção de emergência.

\section{Grupos com homens}

Da mesma forma que ocorreu com os grupos de mulheres, os quatro grupos de homens adultos planejados não tiveram procura. Devido a essa constatação, e pela impossibilidade de realizar grupos de homens informalmente reunidos, já que não freqüentam em número suficiente o ambulatório, as atividades do projeto foram reorientadas de modo a incluir outras estratégias comunitárias que atingissem também o público masculino adulto, conforme descritas a seguir.

\section{Eventos com toda a comunidade}

Nos pontos públicos da favela, como telefone, padaria, bares e outros, foram afixados folhetos sobre o projeto e cartazes sobre prevenção de DST e Aids. Na sala de espera do ambulatório, em todos os horários previstos para consulta médica com grande demanda, foram apresentados vídeos edu- cativos seguidamente, por um período de seis meses, para todos os usuários do serviço. Foram, simultaneamente, colocados à disposição materiais educativos sobre DST/Aids, camisinha masculina e feminina e contracepção de emergência, e fornecidos preservativos masculinos*, femininos** e diafragmas com espermicidas*** para todas as pessoas que demandassem tais métodos.

Para atingir o grupo masculino, foram criadas outras estratégias de alcance mais ampliado na comunidade. Assim, foram realizadas três tardes de rádio abertas à participação dos moradores da Favela Monte Azul, utilizando-se o sistema de alto falantes disponibilizado pela associação comunitária. Esses eventos ocorreram aos sábados, em meses diferentes, com ampla distribuição de camisinhas, folhetos e materiais informativos, além de cartilhas educativas para adolescentes. A programação foi composta por músicas intercaladas com avisos sobre o projeto, falas sobre formas de contaminação e prevenção de DST e Aids, 20 vinhetas sobre gravidez na adolescência, feitas especialmente para rádios, ${ }^{* * * *}$ e depoimentos dos moradores da favela que compareceram buscando camisinhas e materiais educativos. A participação de homens adultos foi mais positiva, como se comentará posteriormente.

A avaliação da intervenção direta na população foi baseada, de um lado, na observação participante das atividades preventivas, com atenção especial para a aceitação e o envolvimento nas atividades propostas e para o conteúdo e significado de falas espontaneamente surgidas durante essas atividades, e, de outro, no controle de saída dos contraceptivos de barreira disponibilizados durante o período de execução do projeto - camisinha masculina, camisinha feminina e diafragma com espermicida.

\section{RESULTADOS}

\section{Avaliação da capacitação dos profissionais de saúde do ambulatório}

A disposição inicial da coordenação do ambulatório para disponibilizar o tempo de trabalho de seus profissionais para as reuniões e atividades de distribuição de camisinha e de exibição de vídeos educativos foi fundamental para o desenvolvimento do projeto. Das 20 pessoas que atuavam no ambulatório, 18 participaram dos dois encontros de capacitação convocados, problematizando e discutindo suas dúvidas e impressões. 
As auxiliares de enfermagem que trabalhavam na recepção do ambulatório aderiram facilmente à proposta de distribuição de preservativos em suas atividades e passaram a se preocupar com prevenção, adquirindo prática na colocação das camisinhas para poder instruir a população. Esse fato é bastante relevante, visto que, no teste prático sobre a colocação de camisinha, realizado antes da capacitação, foi verificado um grau relativamente alto de desconhecimento ou dificuldade em uma série de procedimentos, conforme exposto na Tabela 1.

Das mudanças observadas entre os profissionais que responderam o questionário de pós-teste, observa-se alguma modificação na percepção de risco, surgindo de modo um pouco mais consistente a identificação da vulnerabilidade das mulheres da população local, conforme a Tabela 2. Verificaram-se também ganhos quanto à atenção à Aids em suas ativi- dades profissionais, assim como enriquecimento de suas aptidões para esse trabalho, como pode ser visto na Tabela 3.

Todos os profissionais da área da recepção do ambulatório assumiram a responsabilidade pela distribuição dos materiais educativos e pela exibição dos vídeos em sala de espera. Na distribuição de preservativos masculinos e femininos, mostraram-se empenhados e estimulados pela própria procura dos moradores por esses métodos, fazendo a instrução de uso para quem tivesse dúvidas e contatando prontamente a equipe do projeto sempre que fosse necessária a reposição do estoque.

Entre conversas, reuniões e passagens no ambulatório para o desenvolvimento de pós-testes, observações de sessões de vídeo em sala de espera ou entrega de preservativos, foi possível observar uma recepção

Tabela 1 - Resultados relativos ao teste prático de "colocação da camisinha" em pré e pós-teste para avaliação de capacitação em prevenção de DST e Aids entre profissionais do ambulatório, na favela Monte Azul, São Paulo, SP.

\begin{tabular}{|c|c|c|c|c|c|c|}
\hline \multirow[t]{2}{*}{ Procedimentos } & \multicolumn{2}{|c|}{ Sim } & \multicolumn{2}{|c|}{ Não } & \multicolumn{2}{|c|}{ Total } \\
\hline & $\mathrm{N}$ & $\%$ & $\mathrm{~N}$ & $\%$ & $\mathrm{~N}$ & $\%$ \\
\hline 1. Viu ou comentou sobre data de validade & 4 & $23 \%$ & 14 & $77 \%$ & 18 & $100 \%$ \\
\hline 2. Viu ou comentou sobre embalagem em boas condições/ estufada & 4 & $23 \%$ & 14 & $77 \%$ & 18 & $100 \%$ \\
\hline 3. Viu ou comentou sobre o símbolo do Inmetro & 0 & - & 18 & $100 \%$ & 18 & $100 \%$ \\
\hline 4. Com os dedos (sem usar dentes) & 16 & $89 \%$ & 2 & $11 \%$ & 18 & $100 \%$ \\
\hline 5. Comentou que a colocação deve ser feita com o pênis ereto & 3 & $17 \%$ & 15 & $83 \%$ & 18 & $100 \%$ \\
\hline 6. Colocou na ponta do pênis para desenrolar do lado correto & 16 & $89 \%$ & 2 & $11 \%$ & 18 & $100 \%$ \\
\hline 7. Segurou a ponta apertada para não entrar ar & 11 & $61 \%$ & $\overline{7}$ & $39 \%$ & 18 & $100 \%$ \\
\hline 8. Desenrolou ate o fim, sem esticar pelo lado & 15 & $83 \%$ & 3 & $17 \%$ & 18 & $100 \%$ \\
\hline 9. Comentou que a retirada deve ser com pênis ereto & 7 & $39 \%$ & 11 & $61 \%$ & 18 & $100 \%$ \\
\hline 10. Tirou inteira, sem desenrolar, nem deixar líquido cair & 7 & $39 \%$ & 11 & $61 \%$ & 18 & $100 \%$ \\
\hline
\end{tabular}

Inmetro= Instituto Nacional de Metrologia, Normalização e Qualidade Industrial.

Tabela 2 - Mudanças nas respostas dos profissionais do ambulatório referentes à questão sobre grupos vulneráveis a Aids, por ocasião do pré e do pós-teste na favela Monte Azul. São Paulo, SP.

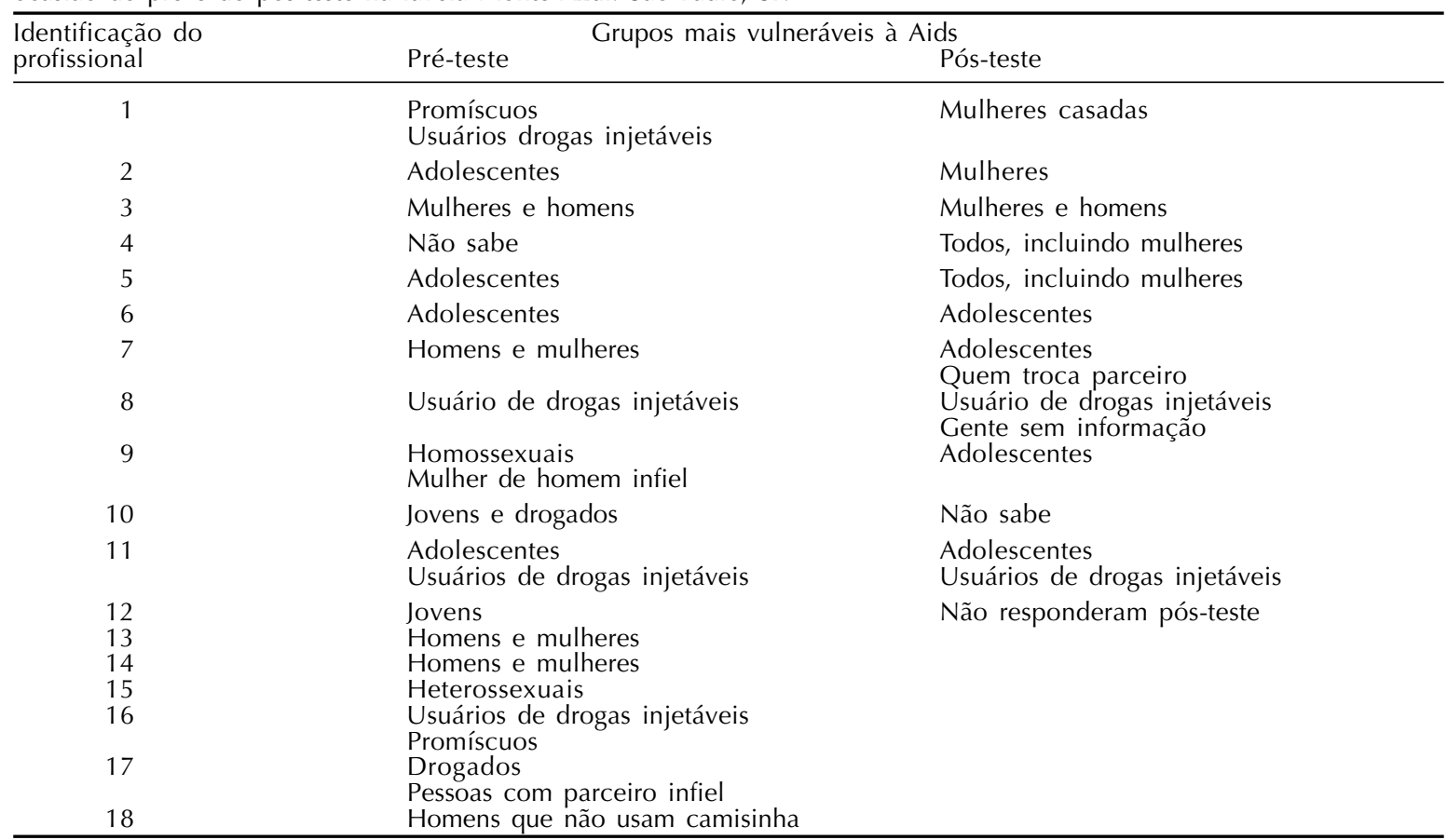


positiva ao projeto por parte dos profissionais. Segundo falas espontâneas anotadas durante conversas informais, foi possível verificar que valorizavam a distribuição de preservativos para a população, especialmente para os adolescentes. Aderiram perfeitamente, também, à divulgação da camisinha feminina, vista como uma novidade benéfica para as mulheres. Também demonstraram interesse em manter atualizados os estoques dos dois tipos de preservativo, preocupando-se em avisar quando estavam em pouca quantidade, garantindo a manutenção e continuidade da distribuição.

Apesar disso, esses profissionais não se dispuseram a implantar rotinas mais complexas sugeridas pela equipe do projeto, como o registro de entregas mensais dos métodos para cada pessoa, restringindose à entrega de cotas de 12 unidades (pré-definidas), não havendo controle de retirada individual nem nenhuma anotação sobre o controle de estoque de cada tipo de preservativo, exceto aquelas realizadas pela própria equipe do projeto.

\section{Avaliação da participação comunitária}

O interesse de vários segmentos da comunidade na busca de materiais educativos foi intenso, principalmente com adolescentes buscando folhetos sobre sexualidade e prevenção da Aids e mulheres buscando folhetos sobre camisinha feminina e sobre contracepção de emergência para si e para amigas e parentes.

A participação da população nas atividades de grupo propostas foi desigual. Das 12 oficinas propostas, foram realizadas quatro com adolescentes, duas com mulheres e nenhuma com homens, devido ao não comparecimento destes.

Participaram dos grupos 70 adolescentes e pré-adolescentes, entre 10 e 17 anos, sendo que, em cada dia de oficina, compareceram cerca de 15 a 20 integrantes. A participação majoritária dessa faixa etária foi masculina, com 59 meninos contra 11 meninas (apenas $15,7 \%$ ). Tal fato chamou bastante a atenção. A responsável pelo projeto foi ativamente procurada

Tabela 3 - Mudanças nas respostas dos profissionais do ambulatório referentes a questão sobre ações de prevenção a Aids no pré e pós -teste na favela Monte Azul. São Paulo, SP.

\begin{tabular}{|c|c|c|c|c|}
\hline \multirow{2}{*}{$\begin{array}{l}\text { Identificação } \\
\text { do profissional }\end{array}$} & \multicolumn{2}{|c|}{$\begin{array}{l}\text { Há ações de prevenção da Aids no seu } \\
\text { procedimento individual? }\end{array}$} & \multicolumn{2}{|c|}{$\begin{array}{l}\text { Como deveria ser feita a prevenção da Aids } \\
\text { neste serviço? }\end{array}$} \\
\hline & Pré-teste & Pós-teste & Pré-teste & Pós-teste \\
\hline 1 & Não & Orientação do uso de camisinha & Com conduta profilática & Com conduta profilática \\
\hline 2 & Não & Encaminhamento para informações & Dando camisinhas & Dando camisinhas \\
\hline 3 & Não & Não & $\begin{array}{l}\text { Esclarecendo dúvidas } \\
\text { Dando camisinhas }\end{array}$ & Esclarecendo dúvidas \\
\hline 4 & Não & $\begin{array}{l}\text { Explico e ensino o uso da camisinha } \\
\text { masculina e feminina }\end{array}$ & $\begin{array}{l}\text { Dando camisinhas } \\
\text { Não sei } \\
\text { Com conduta profilática }\end{array}$ & Dando seringas \\
\hline 5 & $\begin{array}{l}\text { Uso materiais } \\
\text { descartáveis }\end{array}$ & $\begin{array}{l}\text { Oriento a prevenção para usuárias } \\
\text { do pré-natal e ginecologia, com } \\
\text { orientação do uso da camisinha }\end{array}$ & Com material descartável & $\begin{array}{l}\text { Com material descartável } \\
\text { Dando preservativos }\end{array}$ \\
\hline 6 & Dou informações & Dou informações & $\begin{array}{l}\text { Dando Camisinha } \\
\text { Orientando não trocar } \\
\text { parceiros }\end{array}$ & $\begin{array}{l}\text { Dando camisinha } \\
\text { Orientando não trocar } \\
\text { parceiros }\end{array}$ \\
\hline 7 & $\begin{array}{l}\text { Material } \\
\text { descartável }\end{array}$ & $\begin{array}{l}\text { Limpeza, profilaxia e material } \\
\text { descartável }\end{array}$ & Dando camisinhas & Dando camisinhas \\
\hline 8 & Não & $\begin{array}{l}\text { Explico sobre a Aids e oriento } \\
\text { uso da camisinha }\end{array}$ & $\begin{array}{l}\text { Dando camisinhas } \\
\text { Orientando evitar drogas }\end{array}$ & $\begin{array}{l}\text { Dando camisinhas } \\
\text { Evitando materiais } \\
\text { cortantes }\end{array}$ \\
\hline 9 & Conversando & $\begin{array}{l}\text { Esclarecendo sobre Aids } \\
\text { e Incentivando uso da camisinha }\end{array}$ & Dando camisinhas & Dando camisinhas \\
\hline 10 & Não & Não & $\begin{array}{l}\text { Dando camisinhas } \\
\text { Orientando }\end{array}$ & $\begin{array}{l}\text { Fazendo campanha nas } \\
\text { escolas }\end{array}$ \\
\hline 11 & Não & Não & $\begin{array}{l}\text { Dando preservativos } \\
\text { Dando informações }\end{array}$ & $\begin{array}{l}\text { Dando camisinhas } \\
\text { Usando agulhas } \\
\text { descartáveis }\end{array}$ \\
\hline 12 & Não & Não responderam pós-teste & Seringas individuais & Não responderam pós-teste \\
\hline 13 & Incentivar a preve & רção & Usar material descartável & \\
\hline 14 & $\begin{array}{l}\text { Higiene dos mate } \\
\text { de trabalho }\end{array}$ & & $\begin{array}{l}\text { Uso de material de } \\
\text { proteção no trabalho }\end{array}$ & \\
\hline 15 & Dou orientação & & $\begin{array}{l}\text { Informar } \\
\text { Dar camisinha }\end{array}$ & \\
\hline 16 & Dou orientações & & Incentivar o uso da camisi & \\
\hline 17 & Sim (não especific & & $\begin{array}{l}\text { Incentivar o uso de camisi } \\
\text { e dar informação } \\
\text { Usar material descartável } \\
\text { Dar informação }\end{array}$ & \\
\hline
\end{tabular}


volveu três tardes de rádio inicialmente não previstas, procurando atingir esse público. Com essa nova atividade, foi possível mobilizar vários homens que participaram desse evento pela promoção de rodas de capoeira (cantadas ao vivo na programação), pelo envio de discos e discos laser (incluindo, entre as músicas, a divulgação de informações preventivas sobre DST e Aids e vinhetas sobre contracepção, prevenção e gravidez na adolescência) e pela participação em pequenas entrevistas improvisadas, opinando sobre a relevância do tema e da proposta do projeto. Com essa estratégia, foi possível falar com os homens sobre Aids e recolher manifestações:

"Esta rádio é importante porque meu filho vai ouvir, porque ele precisa pegar e usar a camisinha. Viu filhão!"

\section{"É preciso que a menina carregue camisinha, por-} que pode dar pra ele, estar prevenida..." (menina, durante oficina de manuseio da camisinha).

Houve baixo comparecimento nas oficinas propostas para as mulheres (apenas três pessoas em dois dias programados), o que determinou que estas fossem realizadas em conjunto com as pacientes que aguardavam consulta na sala de espera do ambulatório. Assim, dos quatro grupos de mulheres propostos, apenas dois foram realizados. Por esse motivo, tais grupos foram desenvolvidos em tempo mais curto e mesclando metodologia expositiva, complementando as sessões de vídeos educativos que vinham ocorrendo desde o início do projeto.

Durante essas sessões, foram registrados comentários e reações das mulheres. Além da atenção contínua aos diversos temas tratados, chamou a atenção as reações de riso, indignação e crítica frente ao "absurdo da situação" das histórias que abordavam a problemática de gênero, em que havia momentos em que o homem assumia papéis sociais normalmente atribuídos à mulher. Entre esses comentários, há:

"Imagine! Se fosse assim..." (sobre cena em que a mulher sai de casa para trabalhar, deixando o homem com serviço doméstico).

“Já pensou... bêbada?!" (sobre cena em que a mulher aparece em papel masculino, chegando do bar bêbada).

"É doidinho, né?" (sobre cena em que o homem está cuidando da casa e pede xícara de açúcar para o vizinho).

O grupo masculino, como já dito, não compareceu a nenhuma convocação específica proposta. Por esse motivo, o projeto, reformulando estratégias, desen-

\section{"Eu quero que todo mundo se proteja e use ela, que neт еu..."}

Essa participação masculina integrou-se com a mobilização de mulheres e adolescentes, meninos e meninas, que buscaram materiais educativos e camisinhas distribuídas durante as três horas seguidas de cada programa de rádio. Esse tipo de atividade, mais dológicos menos rígidos que os inicialmente propostos, teve mais adesão que as demais estratégias de convocação para realização de grupos.

\section{Avaliação da distribuição de preservativos}

A implantação do projeto, sua divulgação e a colocação de cartazes tiveram um forte impacto sobre as retiradas de preservativo, provavelmente por demanda reprimida, quando não se dispunha desse método. Após esse surto inicial, houve queda na procura, seguida depois de novo aumento nas semanas seguintes aos programas de rádio, quase dobrando o número de retiradas, conforme apontado no Figura.

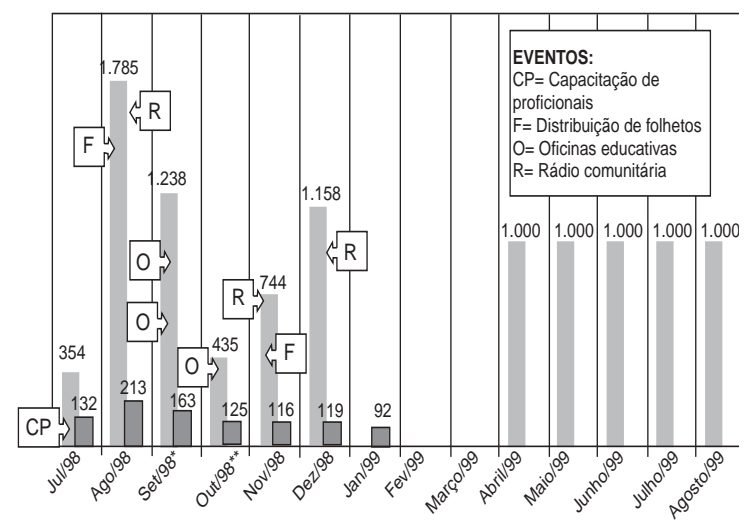

$\overline{\text { Figura - Quantidade de camisinhas retiradas mensalmente }}$ do Ambulatório da Favela Monte Azul, SP. descontraída e festiva, realizada em moldes meto- 
Durante o período de estudo, foram retiradas pela população moradora da favela Monte Azul 7.380 camisinhas masculinas e 1.079 camisinhas femininas quantidade total de ambas disponibilizadas para o estudo. Esse dado aponta haver interesse de procura, seja por aceitação ou curiosidade, por essa população, que antes não dispunha de tais métodos, pois, até o início do estudo, o ambulatório realizava apenas colocação de DIU e venda de pílula anticoncepcional e injeção contraceptiva, ambos a preço de custo.

Também as auxiliares de enfermagem referiram alta procura de camisinhas por homens, mulheres e jovens em geral; elas tiveram, inclusive, de enfrentar desapontamentos e reclamações por parte destes em períodos em que houve falta do método:

"No Carnaval precisou, mas não tinha. O povo queria, acha bom que tenha..."

"Só foi ruim quando procurava e não tinha pra dar. Os meninos diziam que se engravidasse menina - O que é que eu faço?"

O movimento de dispensação dos preservativos (Figura) mostra a grande influência dos programas de rádio e da distribuição ampla de folhetos sobre a retirada de camisinhas masculinas.

\section{Ações desenvolvidas e seu impacto}

Em meados de julho de 1998, foi feita a capacitação de profissionais, e providenciado o equipamento do ambulatório. A distribuição de folhetos e cartazes na favela ocorreu no final de julho, o que provocou um surto inicial de retiradas do preservativo masculino (1.785 unidades) no primeiro mês em que esteve disponível (agosto), provavelmente ligado a novidade do projeto, curiosidade de adolescentes e demanda reprimida.

Em setembro ocorreram duas oficinas com adolescentes e uma com mulheres. Em 19 de setembro de 1998, foi feito o primeiro programa de rádio; após esses eventos houve grande procura por camisinhas masculinas.

Em outubro de 1998, ocorreram um grupo de mulheres e outro com adolescentes, mas não se realizou atividade de rádio. É observada a queda nas retiradas das camisinhas masculinas para 435 unidades.

Em novembro de 1998, foi realizada mais uma oficina com adolescentes, e iniciada a distribuição dos folhetos sobre contracepção de emergência e prevenção de HPV e câncer uterino. Nota-se aumento de retiradas das camisinhas masculinas para 744 unidades, ou seja, quase $50 \%$ a mais que o mês anterior.

Em 29 de novembro de 1998, foi realizado o segundo programa de rádio, o que provocou uma intensa procura de preservativos nas semanas seguintes ao evento, no início de dezembro, que, somado ao outro programa, realizado no dia 13 desse mesmo mês, pareceu ter estimulado a intensa procura. Foram retiradas todas as camisinhas masculinas disponíveis no ambulatório (1.158)

De janeiro a março de 1999, o ambulatório e o projeto ficaram sem preservativos masculinos devido à falta de seu fornecimento pela Secretaria de Estado da Saúde. Segundo registro das profissionais, as pessoas continuaram a perguntar sobre a chegada de novos lotes.

Desde março até hoje, a quantidade de 1.000 unidades/mês de camisinhas masculinas é fornecida regularmente no ambulatório. Durante o projeto, essa quantidade era retirada completamente até a terceira semana de cada mês, em que havia o término de unidades, sendo necessário esperar nova remessa.

As camisinhas femininas foram retiradas com certa média regular (Figura), porém seu fornecimento só ocorreu até janeiro de 1999, depois não houve mais unidades para uso do projeto. Mesmo sem essa disponibilidade, 19 mulheres deixaram voluntariamente seus nomes registrados no ambulatório para a continuidade de uso desse método, caso voltasse a ser distribuído. Como curiosidade registrada, há o depoimento de uma delas, que chegou a ligar para a pesquisadora em busca de mais unidades, afirmando que, além dela, mais dois amigos seus, que estavam fazendo uso desse método (colocando-o em si mesmo, sem o elo interno, para uso com parceiras variadas), queriam continuar a utilizá-lo.

Registra-se, pela procura de pessoas que quiseram deixar nome ou pedido por escrito, que ambos os tipos de camisinha teriam saída caso estivessem disponíveis em maior quantidade para a utilização dessa população.

\section{DISCUSSÃO}

Por meio da intervenção realizada e da observação de seus resultados, foi possível averiguar o grau de sucesso e insucesso de aspectos que envolveram a realização desse projeto, desde a linha de intervenção assumida até sua metodologia e técnicas de execução.

Em primeiro lugar, cabe salientar a importância, 
revelada no estudo, de vincular redução de vulnerabilidade à Aids entre mulheres às questões mais amplas de saúde sexual e reprodutiva. Tanto pelo espaço institucional em que se conseguiu efetivar a intervenção quanto pelo tipo de interesse verificado, essa vinculação parece bem mais propícia à efetividade que aquelas em que se dissocia Aids dos interesses sexuais e reprodutivos ou aquelas que chegam mesmo ao extremo de insistir na prescrição da contenção sexual, como ocorre com a recomendação de redução do número de parceiros. Tal afirmação baseia-se no grande movimento de busca por materiais educativos sobre sexualidade, especialmente por jovens e adolescentes, da busca da camisinha feminina e da curiosidade sobre a contracepção de emergência por parte das mulheres durante a intervenção.

A maioria dos programas de prevenção às DST e à Aids para mulheres dissocia a prevenção da gravidez à prevenção da Aids e parece resgatar antigas formulações do modelo materno-infantil, prevenindo a infecção feminina apenas pelas ações que priorizam o prénatal, a gestação e o parto. ${ }^{2}$ A introdução da dupla prevenção em contracepção, da camisinha feminina e de lubrificantes para uso em relações anais ou vaginais de pouca lubrificação, juntamente à divulgação e à disponibilização da contracepção de emergência, tem sido renegada, assim como a discussão do aborto e da opção de mulheres vivendo com HIV terem filhos. O presente estudo mostrou que, quando oferecidos, ainda que apenas por curiosidade, há efetiva procura por novos métodos preventivos de contracepção e prevenção de DST e Aids, como atestado pela retirada de todas as camisinhas femininas colocadas à disposição. Isto também mostra a necessidade de reformulação de arraigados preconceitos que consideram que métodos de barreira de inserção pela mulher em seu próprio corpo (como o diafragma) são mal vistos, por atentar contra a educação sexual repressora e os tabus religiosos que limitam a mulher a se tocar. Numa comunidade de atitudes tão conservadoras no que diz respeito a papéis de gênero, uma resposta tão positiva quanto a encontrada é bastante estimulante.

As camisinhas femininas foram procuradas e experimentadas por várias mulheres, e 19 chegaram a retornar ao ambulatório, após o término do período de sua distribuição, buscando a continuidade de seu uso. Conseguir ver uma parte do instrumento contraceptivo, mesmo quando inserido no corpo da mulher, seria necessário para trazer-lhe mais segurança, já que o medo de perda de absorventes internos, camisinhas, diafragmas e outros foi registrado no depoimento de mulheres ali residentes? ${ }^{8}$ A camisinha feminina daria, dessa forma, mais segurança às mulheres, tornando-se um meio de (dupla) proteção a ser priorizado? São hipóteses a ser pesquisadas.

A intensa busca por folhetos sobre contracepção de emergência também ressalta a importância de uma abordagem preventiva que una à prevenção da Aids outros aspectos da saúde sexual e reprodutiva, uma vez que os materiais disponibilizados sobre esse método apontavam seu uso como alternativa complementar para utilização emergencial, em caso de falha do preservativo.

Outro aspecto importante a ser discutido é a relação entre a unidade de saúde, os códigos culturais locais e as possibilidades e limites para o trabalho de prevenção.

Foi possível verificar que a unidade de saúde pode ser uma excelente desencadeante e provedora de ações preventivas. Porém, ao mesmo tempo em que provoca um estímulo, principalmente entre as mulheres (principais freqüentadoras dos serviços de saúde), possui limites de alcance com relação aos homens e adolescentes que não costumam freqüentá-la, ainda que possam vir a fazê-lo por um objetivo específico, como a busca por camisinhas.

Foi necessário estar sensível ao movimento espontâneo da própria comunidade, avaliando sua realidade e seus códigos culturais, e à aceitabilidade ou não das ações propostas, para perceber a necessidade do desenvolvimento de ações fora do ambiente do serviço de saúde. Dessa forma, a intervenção procurou se orientar por um diálogo interativo e participativo entre sujeitos realmente envolvidos no processo de ação preventiva que propuseram a intervenção, de um lado, e a comunidade a ser beneficiada, de outro.

O não-comparecimento das mulheres e dos homens às oficinas de prevenção convocadas pelo ambulatório, apesar do interesse e da curiosidade de integração nos momentos de rádio comunitária, reforçou a impressão de que a unidade de saúde é percebida pela população circunvizinha como local de atenção ao doente, e não como instrumento de promoção da saúde. Isto indicou a necessidade de exploração de novos locais e espaços para o desenvolvimento de ações de alcance cultural dentro da própria comunidade (como foi feito com a rádio e com o grupo de adolescentes, utilizando espaços comunitários alternativos ao ambulatório), visando atrair sua participação.

Verifica-se que há, com efeito, a possibilidade de exploração de locais alternativos para ações mais abrangentes, baseando-se, inclusive, numa interpretação das implicações das relações de gênero sobre essas ações.

Os homens adultos se dispuseram a integrar ativi- 
dades preventivas em locais públicos, verificandose uma intensa participação nos programas de rádio. Isto parece refletir o reforço de seu papel cultural de ocupação de espaços públicos e sua "autorização" a abordar assuntos relativos à sua atividade sexual de forma explícita nesses espaços. Sua ausência nas reuniões de grupo, por outro lado, leva a crer que não se interessam por expor tais assuntos em encontros mais restritos em que se adota um discurso mais subjetivo, intimista, típico do espaço privado.

As mulheres adultas, ao contrário, parecem reproduzir a procura por espaços que lhe sejam socialmente destinados, espaços íntimos e menores em que haja pouca aparição pública e mais intimidade entre os participantes. Por isso, a participação nas salas de espera foi intensa, mas nenhuma mulher se dispôs a falar nas rádios. Também entre as adolescentes mulheres parece ter havido uma recusa à exposição pública de seu interesse por temas ligados à sexualidade, como contracepção e prevenção de Aids, já que poucas compareceram aos grupos educativos convocados para adolescentes. No entanto, as adolescentes procuravam cartilhas e materiais em que a leitura era individual, levando exemplares inclusive para irmãs e amigas.

Por fim, há um terceiro aspecto a ser considerado com atenção, e estreitamente relacionado aos anteriores: trata-se da sustentabilidade das ações.

Conforme a realidade constatada no ambulatório na favela Monte Azul, há cada vez menos voluntários da própria comunidade nos trabalhos sociais. Por outro lado, há sobrecarga de tarefas e responsabilidades entre os profissionais desse serviço de saúde, o que limita sua adesão a novos projetos.

Tal fato aponta a necessidade de revisão de estratégias preventivas que implementem projetos contando com a adesão de profissionais a mais tarefas não-remuneradas. É necessária uma análise mais profunda da conjuntura histórica, socioeconômica e política na qual os serviços de saúde estão inseridos, procurando dar o mínimo de suporte para que suas ações sejam sustentáveis. Como manter um esforço dentro da unidade de saúde que extrapole as rotinas da assistência médica tradicional? Melhor: como fazer com que aspectos mais relacionados à prevenção e à promoção da saúde, que dependem de reflexão, debate, estímulo à participação cidadã, possam se tornar rotina nas unidades de saúde? Como articular essa sustentabilidade interna a ações também sustentadas no plano externo à unidade, que são fundamentais para um alcance mais ampliado das ações de prevenção?

\section{CONCLUSÕES}

- A associação de estratégias de distribuição de materiais educativos com a realização de grupos educativos e disponibilização de camisinha feminina e masculina mostrou-se capaz de modificar o padrão de procura por prevenção às DST e à Aids;

- as propostas de atividade via unidade de saúde precisam ser ampliadas pelo desenvolvimento de ações em outros espaços sociais comunitários em que a população transita;

- a participação e adesão às ações preventivas em saúde parecem obedecer a uma diferenciação relacionada às questões de gênero;

- o questionamento de modelos de gênero (comportamentais-relacionais) tradicionais precisa ser debatido no âmbito das ações preventivas, ainda que tenha resultados pouco visíveis em curto prazo;

- a receptividade da camisinha feminina, bem como o interesse por informações sobre a contracepção de emergência, mostra que novas tecnologias preventivas/contraceptivas podem ser do interesse de mulheres de baixa renda;

- é possível desenvolver estratégias preventivas contra as DST e a Aids ancoradas numa perspectiva de saúde sexual e reprodutiva, articulando-as à prevenção da gravidez indesejada;

- são imprescindíveis a discussão e o enfrentamento da questão da sustentabilidade de projetos de intervenção comunitária, revendo o papel do Estado e dos agentes locais na execução das ações, por referência a sua continuidade, recursos e modelos de organização do trabalho.

\section{AGRADECIMENTOS}

À Dra. Wilza Vieira Villela do Instituto de Saúde da Secretaria de Saúde do Estado de São Paulo, que orientou toda a realização do trabalho de campo.

\section{REFERÊNCIAS}

1. Ayres JR, França Jr-I, Calazans G, Saletti Filho H. Vulnerabilidade e prevenção em tempos de Aids. In: Barbosa RM, Parker R, organizadores. Sexualidades pelo avesso: direitos, identidades e poder. Rio de Janeiro: IMS/UERJ; 1999.p.49-72.
2. Barbosa RM, Lago TG. Aids e os direitos reprodutivos: para além da transmissão vertical. In: Parker R, organizador. Políticas, instituições e Aids. Rio de Janeiro: Zahar/ABIA; 1997. p. 163-76. 
3. Barbosa RM. Negociação sexual ou sexo negociado? Poder, gênero e sexualidade em tempos de Aids. In: Barbosa RM, Parker R, organizadores. Sexualidades pelo avesso: direitos, identidades e poder. Rio de Janeiro: IMS/UERJ; 1999. p. 73-88.

4. Boletim Epidemiológico de Aids do Município de São Paulo. São Paulo 1998;2(4).

5. Conselho Nacional de Secretários Municipais de Saúde (Conasems). Brasil atinge 140,3 mil casos de Aids. Bol Conasems 1999; jan/fev.

6. Coordenação Nacional de DST E Aids. Banco de Dados - Aids. Disponível em <URL: http:// www.Aids.gov.br/tabnet.Aids.htm> [2000 ago 10]

7. Figueiredo RMMD. Repensando estereótipos e a mulher frente às DST e Aids para ações de saúde. In: Figueiredo RMMD. Prevenção às DST e Aids em ações de saúde e educação. São Paulo: Nepaids/USP; 1998. p. 23-5.

8. Figueiredo RMMD. Medo, vergonha, machismo ou inibição: e quem não consegue usar a camisinha? (proposta de redução de danos em sexualidade). In: Figueiredo RMMD. Prevenção às DST e Aids em ações de saúde e educação. São Paulo: Nepaids/USP; 1998. p. 26-30.

9. Figueiredo RMMD. Saúde sexual e reprodutiva feminina: favela Monte Azul - um estudo de caso [Dissertação de Mestrado]. São Paulo: Faculdade de Filosofia, Letras e Ciências Humanas da Universidade de São Paulo; 1999.
10. Mann J et al. Solidarity and the future of the global Aids movement. In: Abstracts of the 11th International Conference on Aids; 1996 jul 7-12; Vancouver. Vancouver; 1996.

11. Ministério da Saúde. DATASUS. Disponível em <URL: http://datasus.gov.br> [2000 ago 10]

12. Ministério da Saúde. Assessoria de Comunicação Social e Divisão de Jornalismo. Mortalidade por Aids cai 38\%. Disponível em <URL: http:// Aids.gov.br> [1999 jun 10]

13. Mueller RD, Wasserheit J. A cultura do silêncio: as infecções do trato reprodutivo nas mulheres do terceiro mundo. São Paulo: Coletivo Feminista Sexualidade e Saúde; 1993.

14. Secretaria Municipal da Saúde de São Paulo. Estatísticas. Disponível em <URL: http:// prefeitura.sp.gov.br/secretarias/saude/ estatisticas_proaim_mortalidade2000.asp > [2000 ago 5]

15. Villela W. Vulnerabilidad de las mujeres respecto del VIH. In: Gomez A, editor. Mujeres, vulnerabilidad y SIDA: un enfoque desde los derechos humanos. México: Red de las Mujeres Latinoamericanas y del Caribe; 1998. p. 12-6. (Cad Mujer Salud, 3) 